\title{
Injury in young people with intellectual disability: descriptive epidemiology
}

\author{
J Sherrard, B J Tonge, J Ozanne-Smith
}

\begin{abstract}
Objectives-To assess the public health importance of injury in a representative sample of young people with intellectual disability relative to the general population.

Setting-This study forms part of the Australian Child and Adolescent Development (ACAD) program examining emotional and behavioural problems in a cohort of young people with intellectual disability $(I Q<70)$. The program has collected extensive biopsychosocial data from carers of subjects at two time intervals, $1990(n=579)$ and $1996(n=465)$.

Method-Carer report of medically attended injury to subjects was collected for the first time during 1996 (age 5-29 years) and supplemented with medical record injury data from hospitals and general practitioners for 147 of the ACAD sample and 110 supplementary subjects. These data were compared with general population injury data to assess relative epidemiological differences.
\end{abstract}

Results-Annual injury mortality and morbidity rates were $150 / 100000$ and 55.6 I 1000 persons, with age standardised mortality and morbidity ratios of 8 and 2 respectively. Males and females had similar injury rates. The rate for injury hospitalisations was twice that of the general population. Falls were more common and transport injury and intentional injury less common causes of injury morbidity compared with general population. The patterns of cause, circumstances, and severity of injury in young people with intellectual disability have more similarities with younger children than with their same age group in the general population. Conclusion-This study should alert clinicians and others to the increased risk for injury and possible further handicap in this population. It is essential that injury prevention programs be implemented and evaluated for their effectiveness in reducing the substantial additional burden of suffering, care and cost resulting from injury to young people with intellectual disability.

(Injury Prevention 2001;7:56-61)

Keywords: epidemiology; intellectual disability; mental retardation

Injury is the major preventable public health problem for the general population to age 44 years. ${ }^{12}$ General population injury epidemiology and prevention strategies are well documented, but there is no clear picture quantifying the potential public health impact of injury and relevant prevention for populations with intellectual disability. ${ }^{3-5}$ Increased injury risk in this population is likely because of limitations in both understanding hazards and coping with environmental challenges. ${ }^{36-10}$

This study forms part of the Australian Child and Adolescent Development (ACAD) program examining the emotional and behavioural problems of young people with intellectual disability. ${ }^{89}$ The program sample enrolled in 1989-90 (IQ<70, aged 4-18 years) is representative of young people with intellectual disability known to agencies and schools. ${ }^{11}{ }^{12}$ Subjects live in six large geographic regions across the states of Victoria and New South Wales which contain $60 \%$ of the Australian population (approximately 18 million). ${ }^{13}$ The program has collected an extensive range of biopsychosocial data from carers (parents/ professional carers) of subjects at two time intervals, time $1(1990, \mathrm{n}=579)$ and time 2 (1996, $n=465)$.

Study objectives were to (1) describe the epidemiology of medically attended injury in the ACAD sample using carer data complemented with medical record data and (2) compare findings with the general population to assess relative public health importance.

\section{Method}

SUBJECTS

The sample for carer survey was ACAD program subjects at time 2 . As it was impractical to collect complementary medical record injury data from the 100 hospitals and 250 general practitioners serving all ACAD subjects in the six program regions, data collection was restricted to the largest region (group 1 subjects, $n=147$ ) (fig 1 ).

However, this practical approach limited power for medical record analyses, so a supplementary group of subjects with intellectual disability (group 2 subjects, $n=110$ ) was recruited from the same region using the same procedures as the ACAD program. ${ }^{11}$

\section{DATA COLLECTION}

Carer report

The ACAD program questionnaire sent to carers at time 2 included, for the first time, questions typical of general population injury surveys: number of times the young person with intellectual disability was injured in the previous year, level of medical attention received, and cause of injury. ${ }^{14-17}$ Carers of 


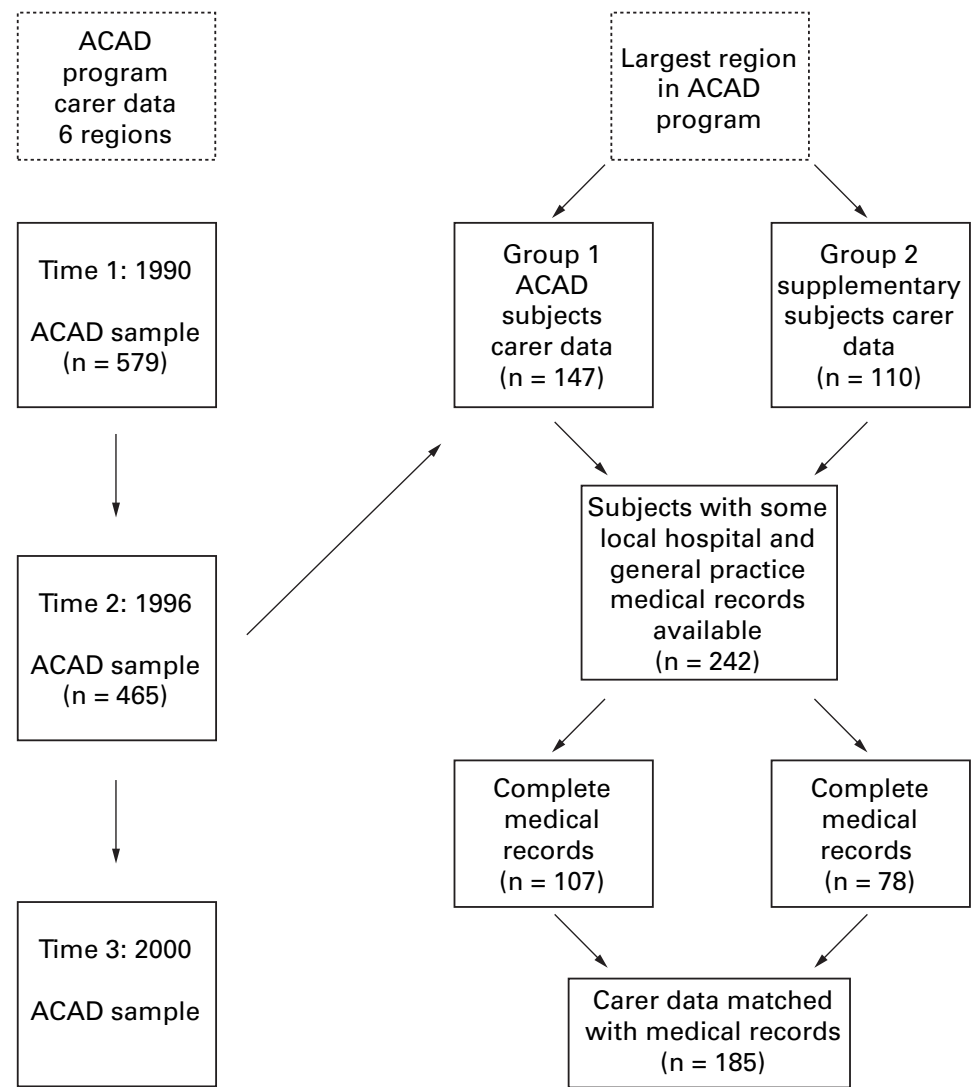

Figure 1 Source of matched data from carer questionnaires and medical records in one of the six geographical regions of the ACAD program.

group 2 subjects were sent the same injury questions (fig 1 ).

\section{Hospital records}

In the region selected for medical record data collection, record administrators in 28 carer nominated hospitals conducted six year (199196) audits for injury admissions and emergency department presentations (fig 1). Major hospitals used the regional computerised systems and also searched for subjects presenting to regional hospitals not nominated by carers. Smaller hospitals without computerised systems conducted manual searches. All hospitals provided audit information using purpose designed forms.

We collected additional admissions data only for subjects in two other of the six regions of the ACAD program to increase power for injury severity analyses. These hospitals also provided general population admission data matched by hospital, sex, and age at admission within one year, to serve as controls (ratio 3:1).

General practice records

Regional general practitioners were asked, as part of a program for continuing vocational registration, to conduct a six year (1991-96) injury audit on their medical records for group 1 and 2 subjects (fig 1 ) ${ }^{18}$ Doctors who declined participation in the vocational program were asked for the audit only. If doctors did not respond, one of the authors (JS) visited doctors where possible. Attempts were made to trace previous doctors if subjects had moved. Audits on purpose designed forms were obtained from $81 \%(88 / 109)$ of doctors.

Deaths

State registries of births, deaths, and marriages and coroner's offices in both states provided database information concerning deaths and inquests for the study group. ${ }^{19}$

Level of intellectual disability

Subject intellectual disability level was scored using IQ data from the state disability databases and verified with existing records. Where necessary, subjects were assessed with standard IQ tests by the ACAD program team.

\section{Comparative general population data}

Comparative age matched general population medical record injury data were extracted from the following databases: (1) the National Injury Surveillance Unit (NISU) mortality collection, (2) a subset of the Victorian Inpatient Minimum Database (VIMD) records, selected by $\mathrm{E}$ codes (external cause of injury codes), ${ }^{20}(3)$ the very detailed Victorian Injury Surveillance System (VISS) with information limited to injury presentations to five major metropolitan and one rural emergency department, ${ }^{21}(4)$ the more recently developed, but less detailed, Victorian Emergency Department Minimum Dataset (VEMD) with a catchment of $80 \%$ of Victorian emergency departments, ${ }^{21}$ and (5) the Extended Latrobe Valley Injury Surveillance (ELVIS) study, a one year prospective collection of injury presentation to general practice in Victoria. ${ }^{18} 2223$

ANALYSES

Carer questionnaire data were checked and cleaned. Trained coders used VIMD, VISS, and VEMD protocols to code medical record data for admissions and presentations to emergency departments and general practice. Injury severity for subject and matched control admissions was scored using the abbreviated injury scale (AIS). Data were stored in Access and analysed using SPSS and 95\% confidence intervals (CI). ${ }^{24-26}$

We estimated the sensitivity $(48.5 \%)$ and specificity $(98.7 \%)$ of carer recall from carer data matched to subject medical records. These estimates were used in Bayes theorem to adjust carer reported injury incidence rates for recall bias and compared with the general population.

The nature and circumstances of injury in the study group and the general population were compared using medical records. Injury severity was compared using the maximum abbreviated injury score (MAIS), the highest single AIS score in an injured patient. ${ }^{27} 28$

\section{Results}

CARER REPORT

Demographics

Carer response rate for ACAD subjects at time 2 was $80.0 \%$ (465/579). Group 1 is representative of program subjects (table 1 ) but group 2 is approximately four years younger. The recruitment rate for group 2 was $71.9 \%(110 / 153)$. 
Table 1 Characteristics of all subjects in the Australian Child and Adolescent Development (ACAD) program at time 2 compared with group 1 ACAD program subjects and group 2 supplementary subjects

\begin{tabular}{|c|c|c|c|}
\hline & $\begin{array}{l}\text { A: } A C A D \text { program } \\
(n=465)\end{array}$ & $\begin{array}{l}\text { B: group } 1 \\
(n=147)\end{array}$ & $\begin{array}{l}\text { C: group } 2 \\
(n=110)\end{array}$ \\
\hline Males \% & $57.8(269)$ & $58.5(86)$ & $63.6(70)$ \\
\hline Mean age $(\mathrm{CI})^{\star}$ & 16.13 & 15.91 & 12.17 \\
\hline \multicolumn{4}{|l|}{ Age group \% (n) } \\
\hline $0-4$ & 0 & 0 & $4.5(5)$ \\
\hline $5-9$ & $5.4(25)$ & $5.4(8)$ & $42.5(50)$ \\
\hline $10-14$ & $37.3(173)$ & $40.1(59)$ & $15.5(17)$ \\
\hline $15-19$ & $31.3(145)$ & $29.3(43)$ & $15.5(17)$ \\
\hline $20-24$ & $23.3(108)$ & $21.8(32)$ & $12.7(14)$ \\
\hline $25-29$ & $2.8(13)$ & $3.4(5)$ & $6.4(7)$ \\
\hline \multicolumn{4}{|c|}{ Intellectual disability level \% } \\
\hline Profound & $4.1(18)$ & $4.2(6)$ & $4.3(4)$ \\
\hline Severe & $23.9(106)$ & $25.2(36)$ & 18.1 (17) \\
\hline Moderate & $41.2(183)$ & $38.5(55)$ & $37.2(35)$ \\
\hline Mild & 30.9 (137) & $32.2(46)$ & $40.4(38)$ \\
\hline Missing & $(21)$ & (5) & (16) \\
\hline
\end{tabular}

${ }^{\star} \mathrm{A}-\mathrm{C}=3.96$ (CI 2.69 to 5.31$), \mathrm{B}-\mathrm{C}=3.74(\mathrm{CI} 2.27$ to 5.19$)$.

Table 2 Carer report of medically attended injury in the previous year for Australian Child and Adolescent Development (ACAD) program subjects and group 2 subjects

\begin{tabular}{llll}
\hline Variable & $\begin{array}{c}\text { ACAD subjects } \\
(n=465)\end{array}$ & $\begin{array}{c}\text { Group } 2 \\
(n=110)\end{array}$ & Difference \\
\hline Incidence of injury events/100/year & 27.5 & 40.9 & 13.4 (CI 3.4 to 23.4) \\
Incidence adjusted for recall bias & 55.6 & 62.5 & 11.6 (CI 2.5 to 20.7) \\
Subjects injured \% (n) & $16.6(77)$ & $28.2(31)$ & \\
Times injured \% (n) & $63.6(49)$ & $64.5(20)$ & \\
$\quad$ Once & $36.4(28)$ & $35.5(11)$ & \\
$\quad$ Two or more & 128 & 45 & \\
Total injuries & $49.1(57)$ & $32.5(14)$ & \\
Frequency of visits for medical attention \% (n) & $62.8(27)$ & \\
$\quad$ General practice & $37.9(44)$ & $4.7(2)$ & \\
Emergency department & $10.3(12)$ & $0.0(0)$ & \\
Admission & $2.7(3)$ & $100.0(43)$ & \\
$\quad$ Other & $100.0(116)$ & & \\
Total visits \% (n) & & 6.9 & 1CI 3.4 to 25.6) \\
Admitted from emergency & 21.4 &
\end{tabular}

«Type of visit (general practice, emergency department, admission) is recorded by carers for up to three separate injury events only. Therefore, totals do not necessarily correspond to the total for "Times injured" which allowed scoring of up to "five or more" separate injury events on the questionnaire.

TThe denominator for calculating proportion of subjects admitted to hospital from emergency department includes the numbers admitted since it is assumed that they would first present to emergency department. This approach is consistent with general population calculations.

There were no differences in age, IQ, or sex distributions between responders and nonresponders in the ACAD program.

Injury

Group 2 had a higher carer reported injury incidence than program subjects (table 2) but there was no difference after adjustment for recall bias. Program subjects were more likely to be hospitalised than group 2 .

Falls caused most injuries to ACAD subjects $(60.2 \%)$ followed by burns $(7.3 \%)$, transport $(5.3 \%)$, and intentional injury $(15.0 \%)$. Injury presentation for subjects at home $(24.9 \%)$ was similar to those in professional care $(26.8 \%)$.

Carer reported injury incidence for males and females was similar (30.1/100 and 24.0/ 100 subjects), but females $(61.5 \%)$ presented to general practice more than males $(41.7 \%)$ : difference 19.8 (CI 1.5 to 38.1).

Injury rates for program subjects aged 5-14 and 15-29 years were similar (29.3/100 and $26.5 / 100$ subjects) and mostly caused by falls (59\% and $61 \%$ respectively). Other injury occurred at low frequency. The pattern of injury in the younger group persisted into the older age group. Younger children (5-9 years) presented to general practice more than emergency departments ( $\chi^{2}$ for trend 12.46, $\mathrm{p}=0.000$ ). Injury incidence was similar across levels of intellectual disability: mild $27.7 / 100$, moderate 23.0/100, severe/profound 33.1/100 subjects.

\section{MEDICAL RECORDS}

Deaths

Five injury deaths occurred in the ACAD program over six years: annual mortality rate 150/ 100000 (CI 50 to 250), indirect age standardised injury mortality ratio $8 .^{29}$ All deaths occurred in males with moderate intellectual disability or below, aged 8-19 years. Three occurred at home (asphyxia with tablet, asphyxia during an epileptic fit, drowning during an epileptic fit), one in hospital (asphyxia with vomits), and one in residential care (asphyxia with vomitus). No suspicious circumstances were found at inquest. The death rate due to asphyxia was substantially higher than the general population (120/100 000 and $0.1 / 100000$ respectively).

\section{Hospital admissions}

Of the 138 injury presentations to emergency departments, 28 were hospitalised (mean age 14.0 years, $75 \%$ male). The proportion admitted $(20 \%)$ reflects carer report (table 2$)$.

The additional admission data $(\mathrm{n}=10)$ collected from the two other ACAD regions, primarily for injury severity analyses, were also included for the following comparisons. Hospitalisations for aspirations were more likely $(28.9 \% v 1.3 \%)$, and transport injury less likely $(10.5 \% v 22.4 \%)$ in the study group than the general population. Differences between the study group and the general population for falls $(31.6 \%$ v $24.2 \%)$, poisoning $(7.9 \%$ v $4.0 \%)$, burns $(5.3 \%$ v $1.3 \%)$, near drowning $(2.6 \% v$ $0.2 \%)$, hit/struck/crush $(2.6 \%$ v $11.4 \%)$, cutting/piercing $(0.0 \%$ v $7.0 \%)$, self injury $(5.3 \%$ v $9.9 \%)$, and assault $(0.0 \%$ v $7.8 \%)$ may be true effects, but low frequencies limit statistical significance.

The study group was more likely to be injured at home $(48.4 \% v 27.1 \%)$ or in professional care $(27.1 \% v 4.3 \%)$ than the general population.

\section{Emergency department and general practice presentations}

Of the 138 emergency department injury presentations, 110 (65\% male) were not hospitalised.

General practice provided 279 complete six year audits on $70.0 \%(180 / 257)$ group 1 and 2 subjects. These audits recorded 193 injuries to 94 subjects ( $65 \%$ males) with no injury to the other 86 subjects.

Data exclude any subsequent presentation for the same injury. The study group had low frequency of injury when divided into five year age groups, so an aggregated age range (5-29 years) and two broad groups (5-14, 15-29 years) were employed for comparative analyses.

Except for significantly lower general practice presentations for study group cutting/ piercing and hit/struck/crush injury, the overall 
Table 3 Cause of injury (E code) ${ }^{20}$ for study group presentations (groups 1 and 2 combined) to emergency departments (non-admissions) and general practice. Comparative medical record $E$ code data for general population injury presentations extracted from the Victorian Emergency Minimum Dataset (VEMD) $)^{21}$ and the Extended Latrobe Valley Injury Surveillance (ELVIS) system ${ }^{18}$

\begin{tabular}{|c|c|c|c|c|}
\hline Cause of injury and $E$ code & $\begin{array}{l}\text { Study group emergency } \\
\text { department } \\
(n=110)\end{array}$ & $\begin{array}{l}\text { Study group general } \\
\text { practice } \\
(n=193)\end{array}$ & $\begin{array}{l}\text { General population } \\
\text { emergency department } \\
\text { VEMD } \\
(n=83154)\end{array}$ & $\begin{array}{l}\text { General population } \\
\text { general practice ELVIS } \\
(n=3027)\end{array}$ \\
\hline Unintentional injury E800-929 & 98.1 & 93.3 & 87.9 & 95.8 \\
\hline Falls E880-888 & 37.5 & 30.7 & 28.8 & 24.6 \\
\hline Transport E800-848 & 7.5 & 9.7 & 11.8 & 8.4 \\
\hline Burns E890-899, 924/.0, .8 & 3.8 & 3.0 & 2.0 & 2.1 \\
\hline Poisoning E850-858, 860-869 & 1.8 & 0.5 & 1.0 & 0.3 \\
\hline Cutting/piercing E920 & 10.3 & 2.1 & 11.5 & 10.0 \\
\hline Hit/struck/crush E917, 918 & 13.2 & 5.9 & 22.1 & 26.5 \\
\hline Other, unintentional E900-909, 911-923, 924/.1, $925-929$ & 24.0 & 41.4 & 22.8 & 23.9 \\
\hline Intentional injury & 1.9 & 6.6 & 7.0 & 3.7 \\
\hline Inflicted by another E960-978, 990-999 & 1.9 & 5.6 & 4.0 & 3.4 \\
\hline Self inflicted E950-959 & 0.0 & 1.0 & 3.0 & 0.3 \\
\hline Undetermined intent E980-989 & 0.0 & 0.0 & 5.0 & 0.1 \\
\hline Adverse effects or complications & 0.0 & 0.0 & 0.1 & 0.5 \\
\hline Total & 100.0 & 100.0 & 100.0 & 100.0 \\
\hline Missing & 3.6 & 4.1 & 6.9 & 0.3 \\
\hline
\end{tabular}

External cause of injury codes (E codes) from the International Classification of Diseases (ninth revision) ${ }^{20}$ and broadly grouped according to the National Injury Surveillance Unit. ${ }^{40}$

patterns and leading causes of injury presenting to emergency and general practice were similar to the general population (table 3 ).

The study group presented to emergency and general practice with more home injury than the general population $(76.7 \% \quad v 32.7 \%$ VISS and $59.3 \% v 23.1 \%$ ELVIS: differences 44.0 (CI 36.0 to 52.0 ) and 36.2 (CI 29.1 to 43.3)). They sustained $80 \%$ of their injuries during leisure/playing while $80 \%$ of general population injuries occurred across a wider range of activities including transport, routine living, sport, and occupation.

Study group patterns for cause of injury presentation to emergency for ages 5-14 and 15-29 years were similar. In contrast, the general population sustained twice the rate for falls in the younger group (47\%), than the older group $(21 \%)$ and a 10 -fold increase in intentional injury for the older group.

The study group pattern for cause of injury presentation to general practice was similar to the general population with falls causing more injury in younger subjects $(40 \%)$ than older subjects $(20 \%)$.

\section{Comparative injury profiles}

Table 4 compares the study group and the general population across all levels of medical care combined (admission, emergency department, general practice).

The incidence of injury in the study group is clearly higher than the general population particularly after adjustment for carer recall bias (table 4). Age standardised morbidity ratio (indirect method) across all levels of medical care is $2.0 .{ }^{29}$ Unlike the general population, the ratio of injured males to females is 1 .

Medical record data confirms carer report of a substantially increased hospitalisation rate for ACAD subjects (table 4). Across all levels of medical care, medical record data show a higher risk for falls, and a lower risk for transport injury and intentional injury for study subjects than the general population.

The difference for falls between carer report and subject medical records may be partly explained by carers misclassifying an injury event involving a bicycle as a fall, rather than a transport injury, on the questionnaire. The difference in carer report and medical records for intentional injury may also be a carer misclassification error due to their misinterpretation of intent, or may be a hospital coding error based on insufficient information in medical records resulting in underestimating intentional injury.

The ratio of injury deaths, admissions, emergency department presentations, and general practice presentations for the study population are similar for carer report (1: 18: 65:84) and medical records (1: 13: 65:122) but differ from the general population (1: 44:312:354).

\section{Injury severity}

Hospitals provided a total of 38 study group admissions matched to 114 general population injury admission controls. Overall, the study group sustained less traumatic injury and substantially more foreign body aspirations than the general population: $63.2 \%$ v $89.5 \%$ (difference 26.3: CI 10.0 to 42.6 ) and $26.3 \%$ v $0.9 \%$ : (difference 25.4: CI 11.3 to 39.5) respectively.

Table 4 Injury profiles by carer report and medical record audit for young people with intellectual disability and the general population for all levels of medically attended injury

\begin{tabular}{|c|c|c|c|}
\hline Injury characteristic & $\begin{array}{l}\text { Carer reported injury } \\
(C I) \\
(n=465)\end{array}$ & $\begin{array}{l}\text { Regional group medical } \\
\text { records (CI) } \\
(n=257)\end{array}$ & $\begin{array}{l}\text { Victorian population } \\
\text { medical records } \\
(n=1650851)\end{array}$ \\
\hline Incidence of injury events/100 persons/year by carer recall & $27.5(23.4$ to 31.6$)$ & & \\
\hline Incidence of injury events $/ 100$ persons/year adjusted for recall bias & 55.6 (Range $41.3-86.0$ ) & & Range $14.5-28.5$ \\
\hline Proportion (\%) of injuries admitted to hospital from emergency department & $21.4(10.7$ to 32.1$)$ & $20.3(14.6$ to 27.0$)$ & 10.4 \\
\hline Proportion (\%) of injury events caused by falls & $60.2(51.2$ to 69.2$)$ & $33.2(29.7$ to 36.7$)$ & 25.2 \\
\hline Proportion (\%) of injury events caused by transport & $5.3(1.2$ to 9.4$)$ & $9.2(7.4$ to 11.0$)$ & 13.9 \\
\hline Proportion (\%) of injury events caused by intentional injury & $15.0(8.4$ to 21.6$)$ & $4.7(3.4$ to 6.0$)$ & 9.8 \\
\hline Male: female ratio for injury events & 1.3 to $1(0.8$ to 1.9$)$ & 1.2 to $1(0.8$ to 1.8$)$ & 2 to 1 \\
\hline
\end{tabular}

*General population injury incidence extrapolated from Victorian data for VIMD, VEMD, and ELVIS combined. 
Figure 2 Injury severity (\%) for hospital admissions in young people with intellectual disability (cases) and young people in the general population (controls) matched by sex, age at admission, and hospital. MAIS grouped for severe (MAIS $\geqslant 3)$, moderate (MAIS =2), and mild (MAIS =1) injury.

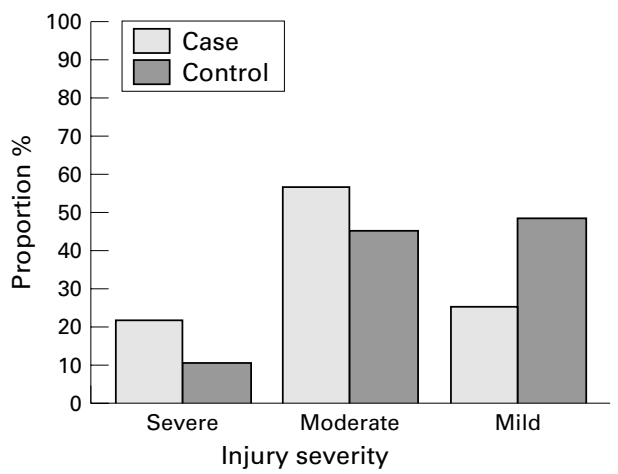

The AIS does not code non-traumatic injury (foreign body aspirations, poisoning, immersion), so we employed the criteria of Walsh and Jarvis $^{28}$ to code foreign body aspirations. Although coding reliability for poisoning and immersion injuries was limited due to insufficient medical record data on both cases and controls, we assumed they were severe for analyses. $^{28}$

MAIS scores were grouped into "severe" (MAIS $\geqslant 3)$, "moderate" (MAIS=2), and "mild" (MAIS=1). Assuming most injuries were single, MAIS groupings for severity are largely equivalent to Walsh and Jarvis ${ }^{28}$ who employed the injury severity scale (ISS) for "severe" (ISS $\geqslant 9$ ), "moderate" (ISS $\geqslant 4$ ), and "mild" (ISS 1-3). This assumption is reasonable, since most injuries were not caused by road trauma where multiple injury is more likely. Figure 2 compares injury severity for all study group and general population hospitalisations.

The odds ratio for all severe injury admissions in the study group was 2.5 (CI 0.9 to 6.8 ) assuming that poisoning and immersion injuries were severe. More reliably, the odds ratio for the study group for severe traumatic injury only (excluding foreign body aspirations, poisoning, immersion) was 6.6 (CI 1.4 to 31.8).

\section{Discussion}

We describe the first Australian and possibly the first international, population based comparative study specifically designed to investigate public health implications of injury in young people with intellectual disability. This group has an eight times excess injury mortality and double the injury morbidity of their counterparts in the general Australian population and populations elsewhere. ${ }^{30}$ The excess mortality is highly associated with asphyxia and drowning. Because mortality data are based on a small sample, any intervention in this area would benefit from a more detailed investigation of asphyxia deaths.

The increased morbidity risk is associated with a higher risk for aspiration and falls hospitalisations. Admissions occur at double the rate and with more severe injury than the general population. It is noteworthy that the childhood pattern of injury for emergency and general practice presentations in the study group (age 5-14) persists into young adult life in sharp

\section{Key points}

- Population based epidemiological data for injury occurrence to those with intellectual disability is minimal.

- Comparative population based epidemiological analyses of young people with and without intellectual disability in Australia was based on injury data collected by carer report and by audit of hospital and general practice medical records.

- Substantially increased risk for injury morbidity in those with intellectual disability is linked with a pattern of cause, circumstances, and severity more typical of young children at home.

- Injury prevention in this vulnerable population is warranted.

- Improved prevention education for hospital, medical, and other service personnel is vital.

- Prevention programs aimed at carers and parents of young children with intellectual disability are required. These programs should target home safety strategies and be maintained into later life with suitable adaptation for the increasing size and mass associated with growing older.

contrast with the general population. It is possible that this childhood pattern at later ages results in higher injury severity because of their greater size and mass. The difference in injury pyramid ratios reflects more severe injury (deaths and hospitalisations) for the study group compared with the general population.

Although our sample size appears small compared with general population injury studies, it is related to the prevalence of intellectual disability and substantial difficulties in case ascertainment and recruitment. Indeed, our sample is among the largest of any published study specifically designed to examine injury in intellectual disability and is representative of a general population of more than 179000 Australian children. ${ }^{11}{ }^{12} 31$ The difference in age of the study group and group 2 (additional regional sample) may have influenced the medical record findings for patterns of injury. However, we consider the influence to be minor as carer report indicated similar patterns of injury for both the 5-14 and 15-29 age groups.

It is recognised that IQ measurement alone is insufficient to characterise intellectual disability and measures of adaptive behaviour, although subjective, are vital for disability services assessment. ${ }^{32}$ However, as IQ is less influenced by environmental setting and social expectations, it is the preferred method for epidemiological research and comparative studies. $^{32-35}$ Avoidance of exposure to injury hazards entails a superior cognitive function to that of recognition alone. ${ }^{36}{ }^{37}$ Given that young people with intellectual disability have a more limited capacity for these functions, their higher injury risk is not unexpected. ${ }^{3}$ 


\section{Implications for prevention}

Our research findings progress the understanding of the relationship between injury and intellectual disability in young people and provide a basis for developing prevention approaches appropriate for young children with a poor understanding of consequences. Allowance would need to be made for their greater size and weight which can influence exposure to hazards and possible injury severity. With safeguards in place, the environment could then be used to advantage for maximising development and physical fitness of the young person with intellectual disability with as little restraint as possible.

There is a need to increase the awareness of health professionals to the potential for injury and possible further handicap in this disabled population. Importantly, parents require substantial information, advice, and guidance for injury prevention in young people with intellectual disability because of the deinstitutionalisation of this population which has transferred the enormous responsibility for daily routine care and possible injury care onto parents.

It is both timely and feasible to implement and evaluate injury prevention programs aimed at improving the quality of life of these young people and their families. ${ }^{38}$ Such programs should provide more information, education, guidance, and on-going support for parents, schools, and disability services concerning specific hazards in home environments and relevant safety approaches. ${ }^{39} 40$ Home visits could include surveillance for change in the presence of hazards and safety items. ${ }^{39}$ General practitioner counseling of parents could enhance falls injury reduction particularly if doctors are supplied with relevant information. ${ }^{41}$

These various approaches to injury prevention in young people with intellectual disability, particularly if coordinated, require investigation and evaluation for effectiveness. If shown to be successful, not only would these families benefit, but potential service and cost savings for hospitals, disability services, and general practitioners would be likely. We gratefully acknowledge the support given by consenting
families and carers of our study group. Monash University Ethics Committee for Human Research granted approval for our ics Committee for Human Research granted approval for our research. Two expert Research Associates at the Monash data. The National Health and Medical Research Council is data. The National Health and Medical Research Council is funding the Australian Child and Adolescent Development
program and provided a doctoral scholarship for the first program and provided a doctoral scholarship for the first author, who was also awarded a Monash University Postgraduate Publication Award.

1 Brown S, Foege W, Bender T, et al. Injury prevention and control: prospects for the 1990s. Annu Rev Public Health control: prospect

2 Nutbeam D, Wise M, Bauman A, et al. Goals and targets for Australia's health in the year 2000 and beyond. Australia: Commonwealth Department of Health Housing and Community Services, 1993

3 Rivara F. Developmental and behavioral issues in childhood injury prevention. F Dev Behav Pediatr 1995;16:362-70.

4 Davidson L, Taylor E, Sandberg S, et al. Hyperactivity in school-age boys and subsequent risk of injury. Pediatrics 1992;90:697-702.

5 Angle C. Locomotor skills and school accidents. Pediatrics 1975;56:819-22.

6 Davidson L. Hyperactivity, antisocial behaviour, and childhood injury: a critical analysis of the literature. $\mathcal{f}$ Dev Behav hood injury: a critical an

7 Dunne R, Asher K, Rivara F. Injuries in young people with developmental disabilities: comparative investigation from 1993;31:83-8.
8 Hyman SL, Fisher W, Mercugliano M, et al. Children with self-injurious behavior. Pediatrics 1990;85(suppl):S437-41. 9 Konarski E, Sutton K, Huffman A. Personal characteristics associated with episodes of injury in a residential facility. Am F Ment Retard 1997;102:37-44.

10 Mellinger G, Manheimer D. An exposure-coping model of accident liability among children. f Health Soc Behav 1967; 8:96-106.

11 Einfeld S, Tonge B. Population prevalence of psychopathology in children and adolescents with intellectual disability: 1 Rationale and methods. F Intellect Disabil Res 1996;40:91-

12 Einfeld S, Tonge B. Population prevalence of psychopathology in children and adolescents with intellectual disability: 2 Epidemiological findings. F Intellect Disabil Res 1996;40: 99-109.

13 Australian Bureau of Statistics. Victorian year book. Commonwealth of Australia, Catalogue No 1301.2, 1998.

14 Bussing R, Menvielle E, Zima B. Relationship between behavioral problems and unintentional injuries in US children. Arch Pediatr Adolesc Med 1996;150:50-6.

15 Alexander C, Ensminger M, Somerfield M, et al. Behavioral risk factors for injury among rural adolescents. Am F Epidemiol 1992;136:673-85.

16 Bijur P, Stewart-Brown S, Butler N. Child behavior and accidental injury in 11,966 preschool children. Am f Dis Child 1986;140:487-92.

17 Harel Y, Overpeck M, Jones D, et al. The effects of recall on estimating annual nonfatal injury rates for children and adolescents. Am F Public Health 1994;84:599-605.

18 Day L, Valuri G, Ozanne-Smith J. General practice injury surveillance in the Latrobe Valley. Melbourne: Monash University Accident Research Centre, Report No 113, 1997.

19 State Coroner's Office. Unnatural deaths. Collated from the findings of the State Coroner 1991/92. Victoria, 1994.

20 United States Department of Health. International classification of diseases. 9th Revision. Clinical Modification (ICD9-CM), 1988

21 Watt G, Ozanne-Smith J. VISS goes electronic: second generation injury surveillance. Hazard 1996;26:1-6.

22 Harrison J, Cripps R. Injury in Australia: an epidemiological review. Canberra: National Injury Surveillance Unit. Australian Institute of Health and Welfare, 1994

23 Ozanne-Smith J. Child injury by developmental stage. Australian fournal of Early Childhood 1992;17:39-48.

24 Norusis M. SPSS for Windows release 6.1. Chicago: SPSS Inc, 1993.

25 Altman D. Practical statistics for medical research. London: Chapman and Hall, 1991.

26 SPSS Inc. SPSS for Windows. Version 8.0 ed. Chicago, IL: SPSS Inc, 1997.

27 Association for the Advancement of Automotive Medicine USA. The abbreviated injury scale. Des Plaines, IL: AAAM, 1990

28 Walsh S, Jarvis S. Measuring the frequency of "severe" accidental injury in childhood. $\mathcal{F}$ Epidemiol Community Health 1992;46:26-32.

29 Armitage P, Berry G. Statistical methods in medical research 2nd Ed. London: Blackwell Scientific Publications, 1987.

30 Gallagher S, Finison K, Guyer B, et al. The incidence of injuries among 87,000 Massachusetts children and adolescents: results of the 1980-81 Statewide Childhood Injury Prevention Program Surveillance System. Am f Public Health 1984;74:1340-7.

31 Einfeld S, Tonge B. Manual for the developmental behaviour checklist $(D B C)$ : primary carer version $(D B C-P)$. Sydney: University of NSW, Monash University, 1992.

32 Fryers T. Epidemiological issues in mental retardation. $\mathcal{f}$ Ment Defic Res 1987;31:365-84.

33 Aman M, Schroeder S. Mental retardation. In: Tonge B, Burrows G, Werry J, eds. Handbook of studies on child psychiatry. Amsterdam: Elsevier Science Publishers, 1990: 215-24.

34 Greenspan S, Granfiels J. Reconsidering the construct of mental retardation: implications of a model of social competence. Am f Ment Retard 1992;96:442-53.

35 Jenkinson J. Diagnosis of developmental disability: psychometrics, behaviour and etiology. Behav Change 1997;14:6072 .

36 Coppens N. Cognitive characteristics as predictors of children's understanding of safety and prevention. F Pediatr Psychol 1986;11:189-202.

37 Pearn J. Children's liability to accidents. In: Berfenstam R, Jackson H, Eriksson B, eds. Conference on The Healthy Community: child safety as a part of health promotion activities. Stockholm: WHO Regional Office for Europe, Copenhagen, 1987: 67-73.

38 Moller J, Kreisfeld R. Progress and current issues in child injury prevention. Adelaide: Australian Institute of Heath and Welfare, National Injury Surveillance Unit, 1997.

39 Roberts I, Kramer M, Suissa S. Does home visiting prevent childhood injury? A systematic review of the literature. BMF 1996;312:29-33.

40 Dowswell T, Towner E, Simpson G, et al. Preventing childhood unintentional injuries-what works. A literature review. Inj Prev 1996;2:140-9.

41 Gielen A, McDonald E, Forrest C, et al. Injury prevention counseling in an urban pediatric clinic. Arch Pediatr Adolesc Med 1997;151:146-51. 